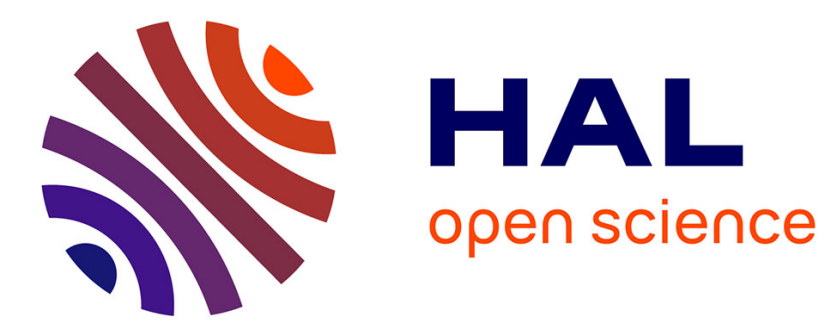

\title{
Flow cytometry evidence about sperm competition in honey bee (Apis mellifera)
}

\author{
Adam Tofilski, Bożena Chuda-Mickiewicz, Krystyna Czekońska, Pawel \\ Chorbiński
}

\section{- To cite this version:}

Adam Tofilski, Bożena Chuda-Mickiewicz, Krystyna Czekońska, Pawel Chorbiński. Flow cytometry evidence about sperm competition in honey bee (Apis mellifera). Apidologie, 2011, 43 (1), pp.63-70. 10.1007/s13592-011-0089-6 . hal-01003627

\section{HAL Id: hal-01003627 \\ https://hal.science/hal-01003627}

Submitted on 1 Jan 2011

HAL is a multi-disciplinary open access archive for the deposit and dissemination of scientific research documents, whether they are published or not. The documents may come from teaching and research institutions in France or abroad, or from public or private research centers.
L'archive ouverte pluridisciplinaire HAL, est destinée au dépôt et à la diffusion de documents scientifiques de niveau recherche, publiés ou non, émanant des établissements d'enseignement et de recherche français ou étrangers, des laboratoires publics ou privés. 


\title{
Flow cytometry evidence about sperm competition in honey bee (Apis mellifera)
}

\author{
Adam Tofilski ${ }^{1}$, Bożena ChudA-Mickiewicz ${ }^{2}$, Krystyna CzeKońsKA $^{1}$, \\ Paweł CHORBIŃSKI ${ }^{3}$
}

\begin{abstract}
${ }^{1}$ Department of Pomology and Apiculture, Agricultural University, 29 Listopada 54, 31-425 Krakow, Poland ${ }^{2}$ Department of Apiculture, West Pomeranian University of Technology, Doktora Judyma 20, 71-466 Szczecin, Poland

${ }^{3}$ Department of Epizootiology and Veterinary Administration with Clinic, University of Environmental and Life Sciences, pl. Grunwaldzki 45, 50-366 Wrocław, Poland
\end{abstract}

Received 9 March 2011 - Revised 21 June 2011 - Accepted 22 July 2011

\begin{abstract}
We tested whether flow cytometry can be used for assessment of viability of honey bee (Apis mellifera) sperm. The method was used to detect possible competition between the sperm of different drones. The flow cytometry analysis of semen stained with SYBR-14/propidium iodide revealed significant differences between fresh and freeze-thawed samples. The identification of populations corresponding to viable and nonviable sperm allowed us to assess the sperm viability. The comparison of single-drone semen with mixed semen of two unrelated drones showed that sperm viability was not affected by mixing, but there were differences between mixed and unmixed semen in side scatter, which correlates with shape and optical homogeneity of particles. The proportion of particles in different populations also was affected by mixing of the semen. The results suggest that there are interactions between ejaculates of different drones, possibly related to sperm competition.
\end{abstract}

\section{honey bee / Apis mellifera / spermatozoa / sperm competition}

\section{INTRODUCTION}

During a single mating flight, the honey bee (Apis mellifera) queen mates with multiple drones (Woyke 1960; Schlüns et al. 2005). Their semen is transferred to the oviducts (Woyke 1956) where it is mixed by contraction of the oviduct muscles (Page 1986). Only a small fraction of spermatozoa reaches the spermatheca and can be used later for fertilization of eggs, and the rest is expelled through the sting chamber (Laidlaw 1944). These circumstances favor intraoviductal sperm competition (Woyciechowski and Król 1996).

Corresponding author: A. Tofilski, rotofils@cyf-kr.edu.pl

Manuscript editor: Klaus Hartfelder
One mechanism of sperm competition is sperm incapacitation, by which substances present in seminal fluid kill the sperm of other males (Harshman and Prout 1994). If this mechanism operates, then mixing the semen of two or more drones should result in higher mortality of spermatozoa. Another possible mechanism of sperm competition is related to sperm polymorphism. In some species, there are two distinct types of sperm. It has been suggested that only one of those types is suitable for fertilization and that the other can block or eliminate the spermatozoa of other males (Swallow and Wilkinson 2002). At the moment, there is no data about the sperm polymorphism in honey bees.

Most of the earlier attempts to confirm sperm competition in honey bees have been unsuc- 
cessful (Harbo 1990; Woyciechowski and Król 1996; Moritz 1986; for review, see Shafir et al. 2009). Analyses of patrilines in honey bee colonies showed that some drones, which mated with the queen, were underrepresented in her offspring (Franck et al. 1999; Haberl and Tautz 1998), but it was not clear if this was the result of sperm competition. In one experiment, the viability of sperm in the presence of seminal fluids of other males was found to be lower than in the presence of only its own seminal fluids (den Boer et al. 2010).

Here we used flow cytometry to verify whether the spermatozoa of two drones show higher mortality after mixing. This method allows quantitative analysis of semen, permits sperm viability to be assessed, and can also detect sperm polymorphism.

\section{MATERIAL AND METHODS}

The drones used in this study came from three unrelated colonies of honey bee (A. m. carnica). In each of the colonies, the queen was caged on the drone comb for $24 \mathrm{~h}$ in order to obtain drones of known age. The experiment was done when the drones were at 20 days of age. Semen was collected in a calibrated capillary tube by standard technique (Laidlaw 1989; Collins and Donoghue 1999). Semen volume was measured by the height of the liquid column in the capillary. The semen was diluted 1:1,000 v:v in Kiev buffer $(0.3 \mathrm{~g}$ glucose, $0.41 \mathrm{~g}$ potassium chloride, $0.21 \mathrm{~g}$ sodium bicarbonate, $2.43 \mathrm{~g}$ sodium citrate per $100 \mathrm{~mL}$ deionized water; Collins and Donoghue 1999). The volume of collected semen was always greater than $0.8 \mu \mathrm{L}$, yielding at least $0.8 \mathrm{~mL}$ diluted sperm. From each sample, $0.5 \mathrm{~mL}$ suspension was mixed with the same volume of a sample collected from an unrelated drone. The remaining volume (at least $0.3 \mathrm{~mL}$ ) of each sample was used for the analysis of unmixed semen (Figure 1).

The order in which the semen was collected and analyzed was controlled to eliminate the effect of the time between collection of the sperm and its analysis. For example, the order of collection was A1, B1, B2, $\mathrm{A} 2, \ldots$ and the order of analysis was A1, B1, A1+B1, $\mathrm{A} 2+\mathrm{B} 2, \mathrm{~B} 2, \mathrm{~A} 2, \ldots$, where the different capital letters indicate different unrelated colonies and the different numbers indicate different drones. The semen of 60 drones was collected and 90 samples were analyzed. There were 60 samples of unmixed semen of single drones and 30 samples of mixed semen of two drones.

In each sample, the proportions of live and dead spermatozoa were determined by SYBR-14/propidium iodide (PI) fluorescent staining with the LIVE/ DEAD Sperm Viability Kit (Molecular Probes L7011). From each sample, $300 \mu \mathrm{L}$ of diluted semen was collected; $5 \mu \mathrm{L}$ SYBR 14 (stock solution, deionized, sterile water 1:50) was added and then incubated for $5 \mathrm{~min}$ at $36^{\circ} \mathrm{C}$. Then $4 \mu \mathrm{L}$ PI was added and stirred. SYBR-14 stains live cells green and PI stains dead cells red. The counts were obtained by flow cytometry (Becton Dickinson FACSCalibur, USA) with a 488-nm argon laser. Green fluorescence was measured in the LFL1 channel and red fluorescence in the LFL3 channel, using the manufacturer's fluorescence compensation filters. Forward scatter and side scatter were also measured. The forward scatter tends to be more sensitive to size of particles and the side scatter tends to be more sensitive to shape and optical homogeneity of particles. Twenty thousand particles were analyzed in each sample. The groups of particles with similar properties are called populations. The cytometry data were analyzed with WinMDI 2.8 software. The red fluorescence, green fluorescence, forward scatter, and side scatter are reported as arbitrary units. Measurements in those units can be compared only within this study.

In order to verify if flow cytometry can be used for assessment of honey bee sperm viability, we conducted freeze-thawing experiment. The experiment allowed us to identify populations with viable and nonviable sperm. Samples of semen from four drones were frozen at $-17^{\circ} \mathrm{C}$ for $2 \mathrm{~h}$ in order to kill the sperm. The samples were analyzed after thawing. Earlier work shows that honey bee sperm does not survive freezing without cryoprotectant (Peng et al. 1992). In the freeze-thawing experiment, each of the four samples consisted of unmixed semen. It was assumed that live spermatozoa are in populations which disappeared after freeze-thawing and dead spermatozoa are in populations which appeared after freeze-thawing. 
Figure 1. Preparation of honey bee semen for flow cytometry. Each of the samples $A$ and $B$ contained semen of single drone and sample $A+B$ contained semen of two drones mixed together.

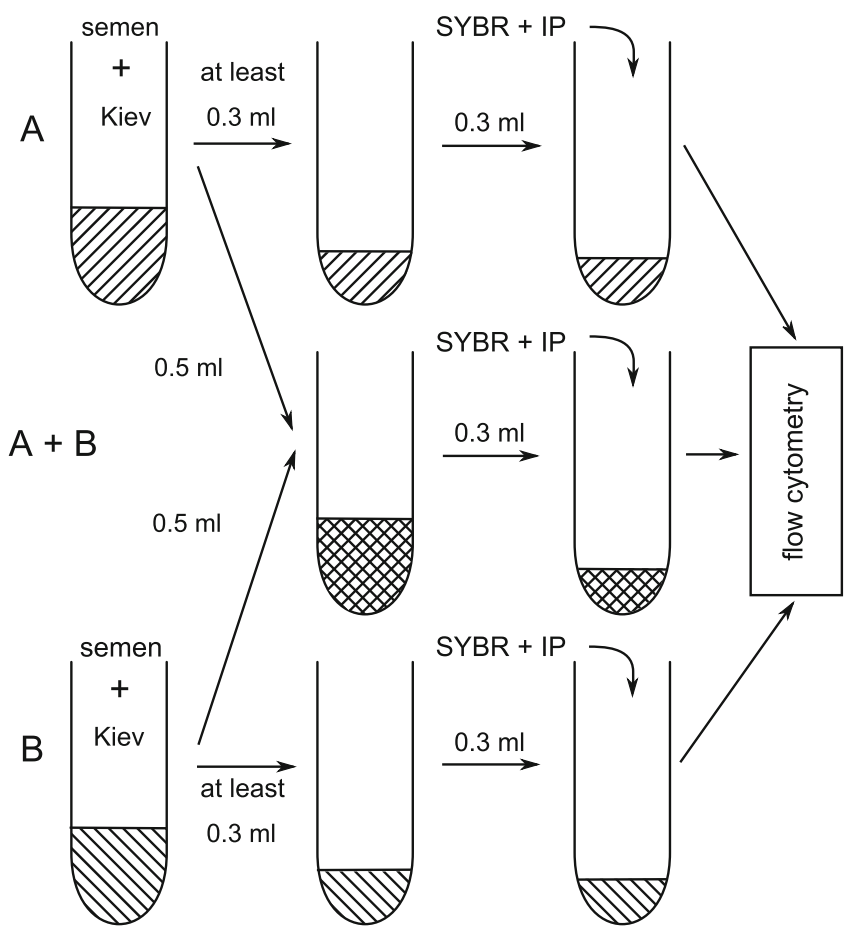

Coming from a total population of semen, the proportions of particles represented in the different flow cytometry populations of a single sample are, of course, not independent from each other, such that when the number of particles increases in any one of these populations, there will be corresponding changes in one or several of the others. Thus, in order to detect changes in particle numbers in any one of the four populations, six ratios were calculated: $n 1 /(n 1+n 2), n 1 /$ $(\mathrm{n} 1+\mathrm{n} 3), \mathrm{n} 1 /(\mathrm{n} 1+\mathrm{n} 4), \mathrm{n} 2 /(\mathrm{n} 2+\mathrm{n} 3), \mathrm{n} 2 /(\mathrm{n} 2+\mathrm{n} 4)$, and $\mathrm{n} 3 /(\mathrm{n} 3+\mathrm{n} 4)$ where $n 1, \mathrm{n} 2, \mathrm{n} 3$, and $\mathrm{n} 4$ correspond to the number of particles in populations $\mathrm{P} 1, \mathrm{P} 2, \mathrm{P} 3$, and P4, respectively. Some of the ratios are independent of each other. For example, if mixing of semen affected number of particles only in population $\mathrm{P} 1$, the ratios $\mathrm{n} 1 /(\mathrm{n} 1+$ $\mathrm{n} 2), \mathrm{n} 1 /(\mathrm{n} 1+\mathrm{n} 3)$, and $\mathrm{n} 1 /(\mathrm{n} 1+\mathrm{n} 4)$ should be affected and ratios $n 2 /(n 2+n 3), n 2 /(n 2+n 4)$, and $n 3 /(n 3+n 4)$ should not be affected.

The differences between populations of particles in forward scatter and side scatter were analyzed using ANOVA. The green and red fluorescence were not included in the comparisons because the populations were determined using those variables. In the statistical analysis of forward scatter and side scatter, sample means were used. In comparing the mixed and unmixed semen, paired Student's $t$ test was used. The pairs consisted of mean values of two unmixed samples and value of sample made by mixing the two samples. The data are presented as means \pm SD. Proportions were arcsin transformed before the statistical analysis.

\section{RESULTS}

In fresh samples of the semen of honey bee drones stained with SYBR-14/PI, there were three main populations of particles (P1, P2, P3), which differed mainly in green fluorescence (Figure 2a, b). After freeze-thawing, there was one new population ( $\mathrm{P} 4)$ of particles showing higher red fluorescence, P1 was still visible, and P2 and P3 disappeared almost completely (Figure 2d). The boundaries of the populations were determined using minima of the red and green fluorescence histograms (Figure 3). The populations differed significantly in forward scatter and side scatter (ANOVA: forward scatter of fresh unmixed samples, $F_{(3,236)}=13.4, P<0.001$; side scatter of fresh unmixed samples, $F_{(3,236)}=61.9 ; P<$ 0.001 ; forward scatter of fresh mixed samples, $F_{(3,116)}=13.6, P<0.001$; side scatter of fresh 


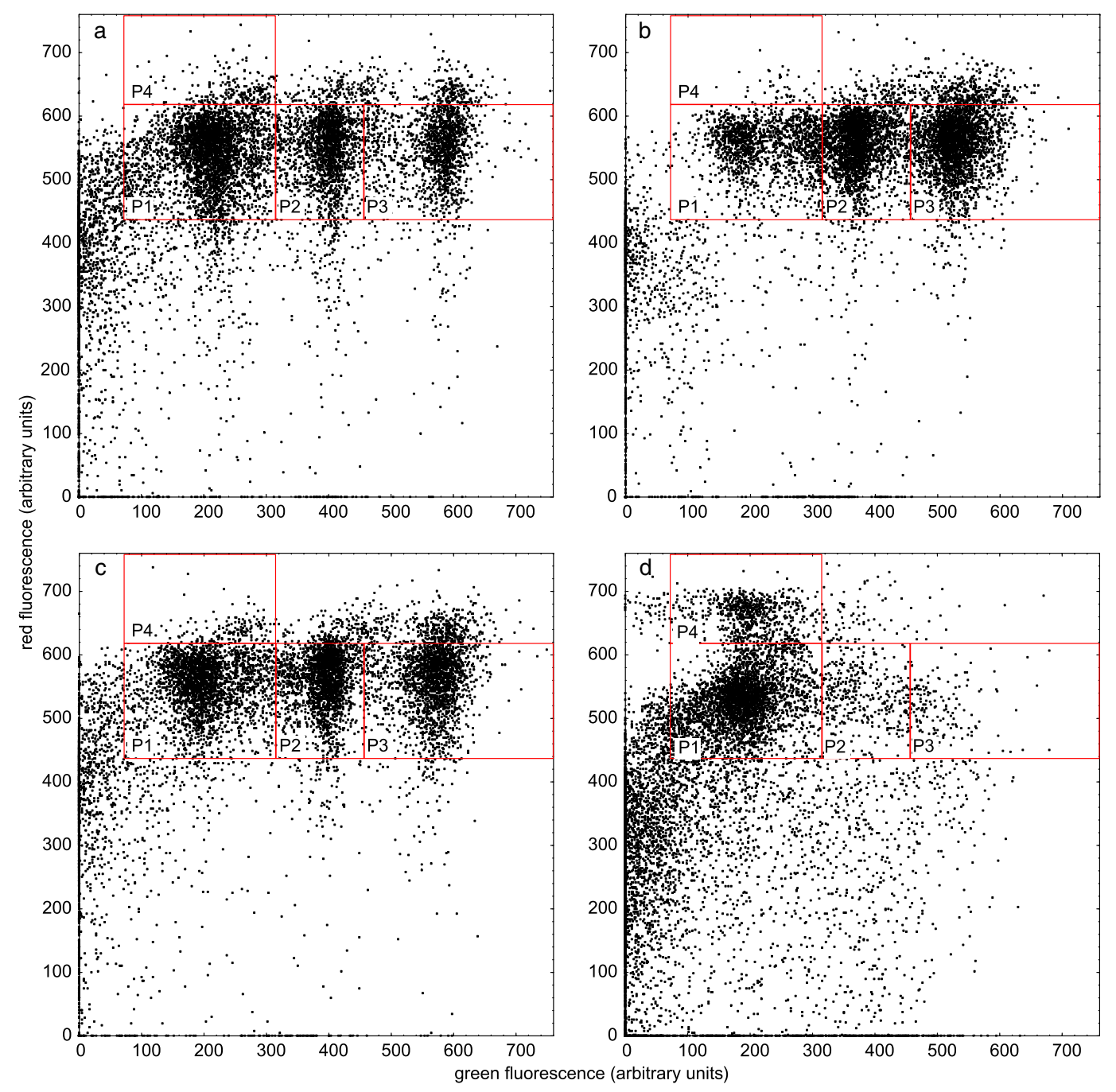

Figure 2. Green and red fluorescence of particles in honey bee semen immediately after collection $(\mathbf{a}, \mathbf{b}, \mathbf{c})$ and after freeze-thawing (d); a, b, d - semen of single drone; $\mathbf{c}$ - mixed semen of the two drones presented at $\mathbf{a}$ and b. Rectangles indicate four populations of particles (P1, P2, P3, P4). Each point represents one particle.

mixed samples, $\left.F_{(3,116)}=50.4 ; P<0.001\right)$. Particles in $\mathrm{P} 1$ differed markedly from particles in all other populations, whereas particles in $\mathrm{P} 2$ and P3 were similar to each other (Table I).

\subsection{Differences between fresh unmixed and freeze-thawed samples}

Freeze-thawed samples differed significantly from fresh unmixed samples in all six proportions calculated from number of particles in the four populations (Table II). After freeze-thawing, the number of particles in P4 increased in comparison to all other populations. Moreover, the number of particles in P2 and P3 decreased in comparison to $\mathrm{P} 1$. Those results (Table II) confirm the above mentioned marked differences between freeze-thawed and fresh samples. From the results, it can be concluded that $\mathrm{P} 1$ did not consist of live cells, P2 and P3 were viable 

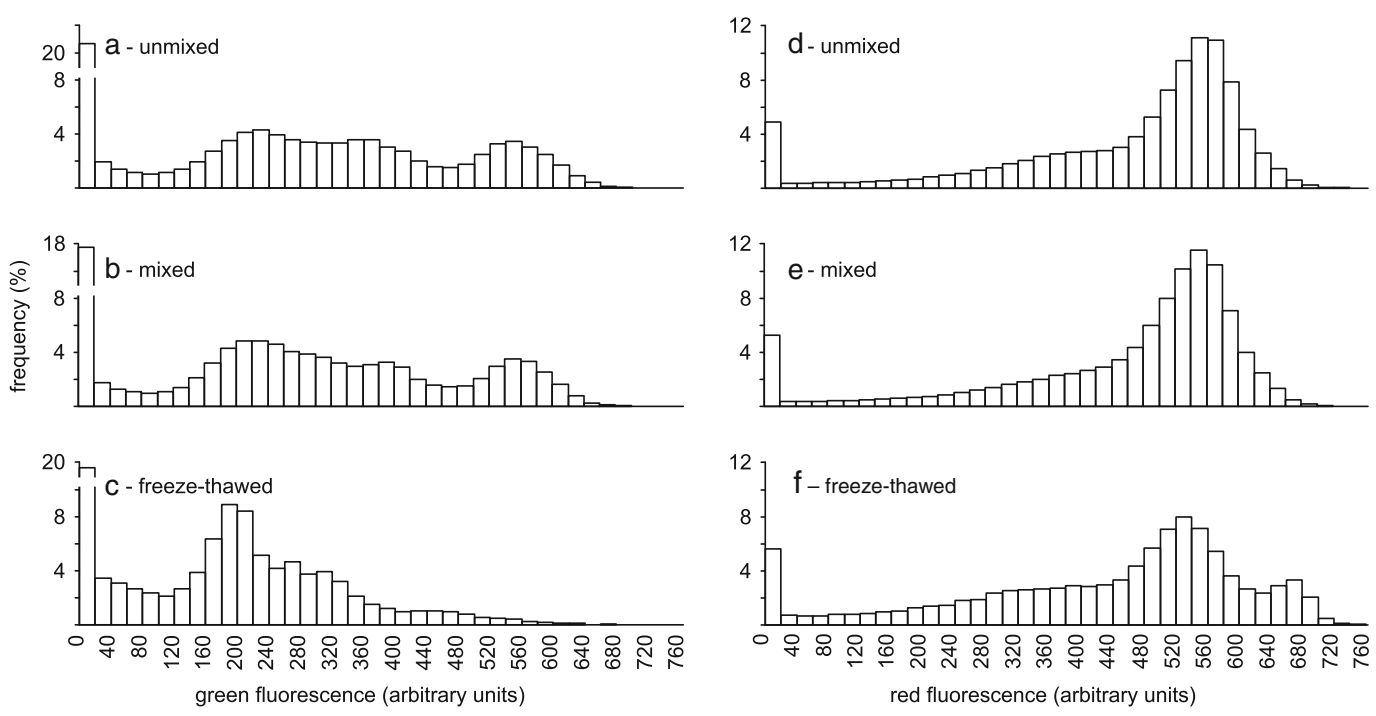

Figure 3. Histograms of green $(\mathbf{a}, \mathbf{b}, \mathbf{c})$ and red $(\mathbf{d}, \mathbf{e}, \mathbf{f})$ fluorescence of particles in honey bee semen stained with SYBR14/PI. The graphs correspond to: samples of fresh semen of one drone (a, d), samples of fresh semen of two drones mixed together $(\mathbf{b}, \mathbf{e})$, and samples of semen of one drone after freeze-thawing $(\mathbf{c}, \mathbf{f})$. The graphs show combined data from all samples in each group.

sperm, and P4 was nonviable sperm. The proportion of live spermatozoa was calculated as $(\mathrm{n} 2+\mathrm{n} 3) /(\mathrm{n} 2+\mathrm{n} 3+\mathrm{n} 4)$. It was significantly lower in freeze-thawed samples $(0.250 \pm 0.152)$ than in fresh unmixed samples $(0.952 \pm 0.048$; Student's $t$ test: $\left.t_{(62)}=-23.5, P<0.001\right)$.

\subsection{Differences between fresh mixed and fresh unmixed samples}

After mixing, there were more particles in P1 in relation to all other populations (Figure 2c).
This can be concluded because the proportions $\mathrm{n} 1 /(\mathrm{n} 1+\mathrm{n} 2), \mathrm{n} 1 /(\mathrm{n} 1+\mathrm{n} 3)$ and $\mathrm{n} 1 /(\mathrm{n} 1+\mathrm{n} 4)$ increased (Table II). In the first two cases, the increase was highly significant (Table II). In the case of the proportion $n 1 /(n 1+n 4)$, the increase was not significant, probably because there was a small number of particles in $\mathrm{P} 4$. Other proportions were not significantly affected by the mixing (Table II), therefore, it can be concluded that mixing has not affected populations other than $\mathrm{P} 1$. The proportion of live spermatozoa $(\mathrm{n} 2+\mathrm{n} 3) /(\mathrm{n} 2+\mathrm{n} 3+\mathrm{n} 4)$ in mixed

Table I. Mean forward scatter and side scatter in four populations of particles (Figure 2) found in unmixed semen of one drone and mixed semen of two drones.

\begin{tabular}{|c|c|c|c|c|c|c|}
\hline \multirow[t]{2}{*}{ Population } & \multicolumn{3}{|l|}{ Forward scatter } & \multicolumn{3}{|l|}{ Side scatter } \\
\hline & Unmixed & Mixed & $P$ & Unmixed & Mixed & $P$ \\
\hline $\mathrm{P} 1$ & $176.9 \pm 69.0 \mathrm{a}$ & $175.9 \pm 52.9 \mathrm{a}$ & 0.644 & $351.6 \pm 14.9 \mathrm{a}$ & $354.0 \pm 12.7 \mathrm{a}$ & $<0.001$ \\
\hline $\mathrm{P} 2$ & $246.2 \pm 61.6 \mathrm{bc}$ & $249.4 \pm 43.1 \mathrm{bc}$ & 0.282 & $375.0 \pm 20.9 \mathrm{~b}$ & $378.3 \pm 18.3 b$ & $<0.001$ \\
\hline $\mathrm{P} 3$ & $232.7 \pm 72.3 \mathrm{~b}$ & $234.9 \pm 52.7 \mathrm{~b}$ & 0.539 & $377.2 \pm 12.2 \mathrm{~b}$ & $380.5 \pm 11.4 \mathrm{~b}$ & $<0.001$ \\
\hline $\mathrm{P} 4$ & $267.5 \pm 113.8 \mathrm{c}$ & $274.6 \pm 89.8 \mathrm{c}$ & 0.199 & $392.5 \pm 17.3 \mathrm{c}$ & $398.5 \pm 12.9 \mathrm{c}$ & $<0.001$ \\
\hline
\end{tabular}

$P$ values indicate significance of differences between unmixed and mixed samples (paired Student's $t$ test). Within columns, means $( \pm \mathrm{SD})$ followed by the same letters are not significantly different $(P>0.05)$ using Duncan's multiple range test 
Table II. Mean proportions of number of particles from four populations found in honey bee semen.

\begin{tabular}{|c|c|c|c|c|c|}
\hline \multirow[t]{2}{*}{ Proportion } & \multirow{2}{*}{$\begin{array}{l}\text { Freeze- } \\
\text { thawed }\end{array}$} & \multicolumn{2}{|l|}{ Fresh } & \multirow{2}{*}{$\begin{array}{l}\text { Student's } t \text { test } \\
\text { freeze-thawed vs. unmixed }\end{array}$} & \multirow{2}{*}{$\begin{array}{l}\text { Paired Student's } \\
t \text { test unmixed vs. mixed }\end{array}$} \\
\hline & & Unmixed & Mixed & & \\
\hline $\mathrm{n} 1 /(\mathrm{n} 1+\mathrm{n} 2)$ & 0.918 & 0.649 & 0.692 & $P<0.001$ & $P<0.001$ \\
\hline $\mathrm{n} 1 /(\mathrm{n} 1+\mathrm{n} 3)$ & 0.962 & 0.605 & 0.649 & $P<0.001$ & $P<0.001$ \\
\hline $\mathrm{n} 1 /(\mathrm{n} 1+\mathrm{n} 4)$ & 0.844 & 0.952 & 0.956 & $P<0.001$ & $P=0.580$ \\
\hline $\mathrm{n} 2 /(\mathrm{n} 2+\mathrm{n} 3)$ & 0.282 & 0.550 & 0.550 & $P<0.001$ & $P=0.991$ \\
\hline $\mathrm{n} 2 /(\mathrm{n} 2+\mathrm{n} 4)$ & 0.321 & 0.901 & 0.899 & $P<0.001$ & $P=0.499$ \\
\hline $\mathrm{n} 3 /(\mathrm{n} 3+\mathrm{n} 4)$ & 0.176 & 0.918 & 0.915 & $P<0.001$ & $P=0.456$ \\
\hline
\end{tabular}

The semen was analyzed immediately after collection (fresh) or after freeze-thawing. The fresh samples consisted of semen of one drone (unmixed) or semen of two drones mixed together. n1, n2, n3, and n4 correspond to number of particles in populations P1, P2, P3, and P4 (Figure 2), respectively

semen $(0.952 \pm 0.025)$ and unmixed semen $(0.952 \pm 0.048)$ did not differ significantly (paired Student's $t$ test: $t_{(29)}=-0.53, P=0.599$ ). After mixing, each of P1, P2, P3, and P4 showed significantly higher side scatter (Table I). The effect of mixing on forward scatter was not statistically significant (Table I).

\section{DISCUSSION}

The results presented here show that mixing of sperm from different drones does not affect their viability. This is in agreement with some studies (Woyciechowski and Król 1996; Shafir et al. 2009) but not with the other work (den Boer et al. 2010). The difference in results may be related to the methods of semen collection. When the semen was collected from ejaculation (Woyciechowski and Król 1996; Shafir et al. 2009; this study), there was no difference in sperm mortality between mixed and unmixed semen. The expected higher mortality of sperm was found when the semen was collected from dissected seminal vesicles and mixed with content of accessory glands dissected from other drones (den Boer et al. 2010). It is not clear whether the second experimental setup (den Boer et al. 2010) reflects natural conditions. Immediately after copulation, there is usually only semen inside the queen's lateral oviducts (Woyke 1960). Mucus and whitish substance containing epithe- lial membrane from the accessory gland is in the queen's bursa copulatrix (Ruttner 1956; Woyke and Ruttner 1958; Woyke 2010) and, together with parts of endophallus, it forms mating plug (Woyciechowski et al. 1994) called mating sign. Before the next drone is able to transfer its semen to the oviducts, it needs to remove the mating sign of the previous drone. There is little contact between the accessory gland secretion of one drone and the semen of another drone.

We cannot exclude the possibility that, in natural conditions, mortality of mixed sperm is higher. In the experiment presented here, the semen was diluted with Kiev buffer before it was mixed. It is possible that at low concentrations, hypothetical factors responsible for mortality of spermatozoa are not active.

Side scatter and proportion of particles in the populations changed significantly after the semen of different drones was mixed. At least some of the changes may be related to sperm competition. It is particularly interesting that after mixing the proportion of particles in P1 (believed to be nonviable particles) increased in relation to other populations, although in the other populations the proportions of particles remained similar (Table II). One possible explanation of this result is that the number of particles in P1 increased as a result of coagulation. In other insects, coagulation of seminal fluids is important for formation of the mating plug (Rogers et al. 2009). In Drosophila melanogaster, the mating plug con- 
sists of PEB-me protein, which shows autofluorescence (Lung and Wolfner 2001). In primates, there is some evidence that coagulation of seminal fluids is related to sperm competition (Dixson and Anderson 2002). It is possible that honey bee proteins present in semen coagulate when in contact with the spermatozoa of another drone in order to immobilize them. The coagulation on the surface of spermatozoa could explain the differences in the side scatter between mixed and unmixed samples. It is not clear what the source of hypothetical factors causing the coagulation is. They can be present in seminal fluid filling the space between spermatozoa and their origin can be seminal vesicles. However more research is required to confirm the coagulation and identify source of the hypothetical coagulation factors.

Flow cytometry allowed us to detect in honey bee semen two different populations of live spermatozoa (P2 and P3). This suggests the presence of sperm polymorphism, which has been found in many systematic groups of invertebrates (Swallow and Wilkinson 2002). In honey bee, the morphological differences between sperm populations may be small and therefore overlooked despite a great many microscopic observations. Such small differences can easily be detected by flow cytometry, which can measure a large number of particles. This method has been used to detect subpopulations of sperm in semen of boar (Pena et al. 2005; Thurston et al. 2001; Abaigar et al. 1999), dog (Martinez et al. 2006), and gazelle (Abaigar et al. 1999). It is important to explain the differences between the populations of particles in honey bee semen; this can be achieved by combining flow cytometry analysis with fluorescence microscopy observations.

It is known from earlier studies based on microscopic observations that live spermatozoa are fluorescent green and the dead ones are fluorescent red when stained with SYBR-14/PI (Collins and Donoghue 1999). The same staining method combined with flow cytometry gives large samples and makes blind counting easier (Holman 2009). Flow cytometry has been used to study hemocytes of honey bee (de Graaf et al.
2002) and sperm of ants (Cournault and Aron 2008). The freeze-thawing experiment presented here confirmed that flow cytometry can be used to assess the mortality of spermatozoa. This method allows quantitative analysis of semen and permits detection of sperm polymorphism.

\section{ACKNOWLEDGEMENTS}

We thank Michael Jacobs and two anonymous reviewers for helpful comments on earlier versions of this paper and Beata Ochał and Iwona Zbyryt for technical assistance. This work was supported by Ministry of Science and Higher Education grant No. N N311 292436.

Mise en évidence d'une compétition spermatique chez l'abeille (Apis mellifera) par la méthode de cytométrie en flux

Spermatozoïde / compétition spermatique / Apis mellifera

Mittel Durchflusszytometrie gewonnene Erkenntnisse zur Sperma-Kompetition bei der Honigbienene (Apis mellifera)

\section{Honigbiene / Spermien / Sperma-Kompetition}

Open Access This article is distributed under the terms of the Creative Commons Attribution Noncommercial License which permits any noncommercial use, distribution, and reproduction in any medium, provided the original author(s) and source are credited.

\section{REFERENCES}

Abaigar, T., Holt, W.V., Harrison, R.A.P., del Barrio, G. (1999) Sperm subpopulations in boar (Sus scrofa) and Gazelle (Gazella dama mhorr) semen as revealed by pattern analysis of computer-assisted motility assessments. Biol. Reprod. 60, 32-41

Collins, A.M., Donoghue, A.M. (1999) Viability assessment of honey bee, Apis mellifera sperm using dual fluorescent staining. Theriogenology 51, 1513-1523

Cournault, L., Aron, S. (2008) Rapid determination of sperm number in ant queens by flow cytometry. Insect. Soc. 55, 283-287

de Graaf, D.C., Dauwe, R., Walravens, K., Jacobs, F.J. (2002) Flow cytometric analysis of lectin-stained 
haemocytes of the honeybee (Apis mellifera). Apidologie 33, 571-579

den Boer, S.P.A., Baer, B., Boomsma, J.J. (2010) Seminal fluid mediates ejaculate competition in social insects. Science 327, 1506-1509

Dixson, A.F., Anderson, M.J. (2002) Sexual selection, seminal coagulation and copulatory plug formation in primates. Folia Primatol. 73, 63-69

Franck, P., Coussy, H., LeConte, Y., Solignac, R., Garnery, L., Cornuet, J.M. (1999) Microsatellite analysis of sperm admixture in honeybee. Insect Mol Biol. 8, 419-421

Haberl, M., Tautz, D. (1998) Sperm usage in honey bees. Behav. Ecol. Sociobiol. 42, 247-255

Harbo, J.R. (1990) Artificial mixing of spermatozoa from honeybees and evidence for sperm competition. J. Apic. Res. 29, 151-158

Harshman, L.G., Prout, T. (1994) Sperm displacement without sperm transfer in Drosophila melanogaster. Evolution 48, 758-766

Holman, L. (2009) Sperm viability staining in ecology and evolution: potential pitfalls. Behav. Ecol. Sociobiol. 63, 1679-1688

Laidlaw, H.H. (1944) Artificial insemination of the queen bee (Apis mellifera $\mathrm{L}$ ): morphological basis and results. J. Morphol. 74, 429-465

Laidlaw Jr., H.H. (1989) Instrumental insemination of honey bee queens. Dadant \& Sons, Hamilton

Lung, O., Wolfner, M.F. (2001) Identification and characterization of the major Drosophila melanogaster mating plug protein. Insect Biochem Mol. Biol. 31, 543-551

Martinez, I.N., Moran, J.M., Pena, F.J. (2006) Two-step cluster procedure after principal component analysis identifies sperm subpopulations in canine ejaculates and its relation to cryoresistance. J. Androl. 27, 596-603

Moritz, R.F.A. (1986) Intracolonial worker relationship and sperm competition in the honeybee (Apis mellifera L.). Experientia 42, 445-448

Page, R.E. (1986) Sperm utilization in social insects. Ann. Rev. Entomol. 31, 359-361

Pena, F.J., Saravia, F., Garcia-Herreros, M., Nunezmartinez, I., Tapia, J.A., Johannisson, A., Wallgren, M., Rodriguez-Martinez, H. (2005) Identification of sperm morphometric subpopulations in two different portions of the boar ejaculate and its relation to postthaw quality. J. Androl. 26, 716-723

Peng, C.Y., Yin, C., Yin, L.R.S. (1992) Effect of rapid freezing and thawing on cellular integrity of honey bee sperm. Physiol. Entomol. 17, 269-276

Rogers, D.W., Baldini, F., Battaglia, F., Panico, M., Dell, A., Morris, H.R., Catteruccia, F. (2009) Transglutaminasemediated semen coagulation controls sperm storage in the malaria mosquito. PLoS Biol. 7, e1000272

Ruttner, F. (1956) Zur Frage der Spermaübertragung bei der Bienenkönigin. Insect. Soc. 3, 351-359

Schlüns, H., Moritz, R.F.A., Neumann, P., Kryger, P., Koeniger, G. (2005) Multiple nuptial flights, sperm transfer and the evolution of extreme polyandry in honeybee queens. Anim. Behav. 70, 125-131

Shafir, S., Kabanoff, L., Duncan, M., Oldroyd, B.P. (2009) Honey bee (Apis mellifera) sperm competition in vitro - two are no less viable than one. Apidologie 40, 556-561

Swallow, J.G., Wilkinson, G.S. (2002) The long and short of sperm polymorphisms in insects. Biol. Rev. 77, 153-182

Thurston, L.M., Watson, P.F., Mileham, A.J., Holt, W.V. (2001) Morphologically distinct sperm subpopulations defined by Fourier shape descriptors in fresh ejaculates correlate with variation in boar semen quality following cryopreservation. J. Androl. 22, 382-394

Woyciechowski, M., Kabat, L., Krol, E. (1994) The function of the mating sign in honey bees, Apis mellifera L.: new evidence. Anim. Behav. 47, 733-735

Woyciechowski, M., Król, E. (1996) On intraoviductal sperm competition in the honeybee (Apis mellifera). Folia Biol. (Krakow) 44, 1-2

Woyke, J. (1956) Anatomo-physiological changes in queenbees returning from mating flights, and the process of multiple mating. Bull. Acad. Polon. Sci. 4, 81-87

Woyke, J. (1960) Natural and artificial insemination of queen honey bees. Pszczel. Zesz. Nauk. 4, 183-273

Woyke, J. (2010) Three substances ejected by Apis mellifera drones from everted endophallus and during natural matings with queen bees. Apidologie 41, 613-621

Woyke, J., Ruttner, F. (1958) An anatomical study of the mating process in the honeybee. Bee World 39, $3-18$ 